
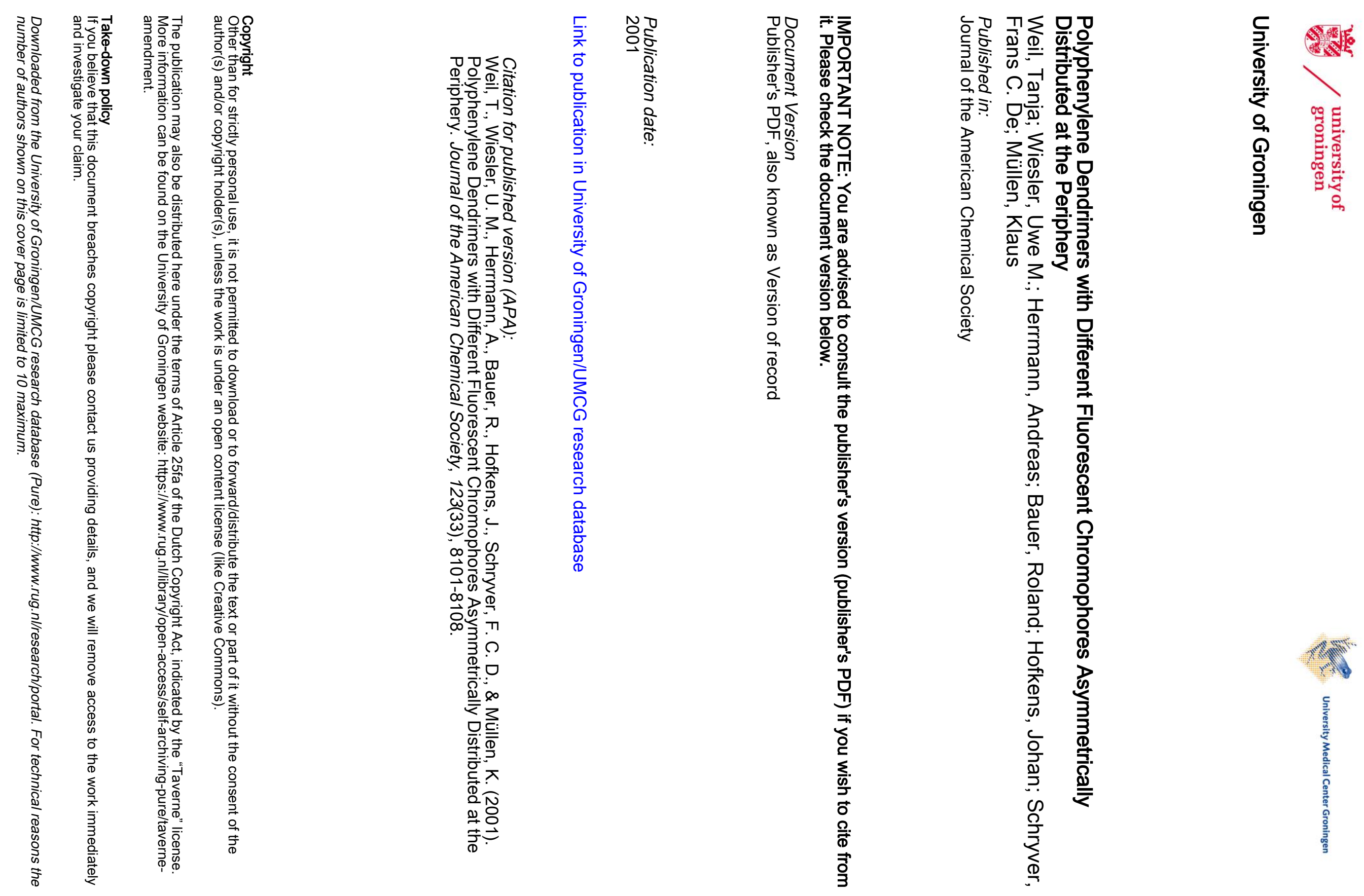


\title{
Polyphenylene Dendrimers with Different Fluorescent Chromophores Asymmetrically Distributed at the Periphery
}

\author{
Tanja Weil, Uwe M. Wiesler, Andreas Herrmann, Roland Bauer, Johan Hofkens, \\ Frans C. De Schryver, ${ }^{\ddagger}$ and Klaus Miillen*
}

\begin{abstract}
Contribution from the Max-Planck-Institut fü Polymerforschung, Ackermannweg 10, 55128 Mainz, Germany, and Department of Chemistry, Katholieke Universiteit Leuven, Celestijnenlaan 200F, 3001 Heverlee, Belgium
\end{abstract}

Received March 5, 2001

\begin{abstract}
A new synthetic approach leading to asymmetrically substituted polyphenylene dendrimers is presented. Following this method, polyphenylene dendrimers decorated with an increasing number of chromophores at the periphery have been obtained up to the second generation. Especially the synthesis of a polyphenylene dendrimer bearing three donor chromophores and one acceptor chromophore has been realized. Intramolecular energy transfer within this molecule is demonstrated by applying absorption and fluorescence measurements.
\end{abstract}

\section{Introduction}

In recent years there has been an increasing interest in the design of macromolecules on the nanometer scale. ${ }^{1}$ Among these nanoobjects, dendrimers play an important role, which is due to their distinct size, monodispersity, and the ease of introduction of functional groups. ${ }^{2,3}$ Some effort has been made toward the synthesis of dendrimers bearing more than one type of functional group at the periphery. ${ }^{4}$ Only the convergent approach allows an accurate control over the number and placement of functionalities and therefore fulfils the requirement for the buildup of asymmetric surface-functionalized dendrimers. Fréchet and co-workers were able to introduce two different functions via the convergent attachment of two differently substituted poly(aryl ether) dendrons to a bifunctional core. ${ }^{5}$ In this way fascinating new molecules such as amphiphilic dendrimers coated with carboxylic acid groups on one-half and alkyl chains on the other ${ }^{6-9}$ or molecular dipole ${ }^{10}$ have been synthesized. Recently, there have been a few examples of dendrimers carrying multiple functions in close proximity to each other ${ }^{11-14}$

* Address correspondence to this author: Max-Planck-Institut für Polymerforschung; (Phone/Fax) ++49-6131-379151; (e-mail) muellen@mpipmainz.mpg.de.

$\ddagger$ Katholieke Universiteit Leuven.

(1) Adler, H. J.; Fischer, P.; Heller, A.; Jansen, I.; Kuckling, D.; Komber, H.; Lehmann, D.; Piontek, J.; Pleul, D.; Simon, F. Acta Polym. 1999, 50, 132.

(2) Newkome, G. R.; Moorefield, C. N.; Vögtle, F. Dendritic Molecules; VCH Verlagsgesellschaft mbH: Weinheim, Germany, 1996.

(3) Fischer, M.; Vögtle, F. Angew. Chem., Int. Ed. Engl. 1999, 38, 884.

(4) Freeman, A. W.; Christoffels, L. A. J.; Frechet, J. M. J. J. Org. Chem. $\mathbf{2 0 0 0}, 65,7612$

(5) Leon, J. W.; Frechet, J. M. J. Polym. Bull. 1995, 35, 449

(6) Sanford, E. M.; Frechet, J. M. J.; Wooley, K. L.; Hawker, C. J. Polym. Prepr. 1993, 34, 654.

(7) Hawker, C. J.; Wooley, K. L.; Frechet, J. M. J. J. Chem. Soc., Perkin Trans. 1 1993, 12, 1287.

(8) Hawker, C. J.; Wooley, K. L.; Frechet, J. M. J. Polym. Prepr. 1993, $34,54$.

(9) Frechet, J. M. J.; Hawker, C. J.; Wooley, K. L. J. M. S. Pure Appl. Chem. 1994, A31, 1627.

(10) Wooley, K. L.; Hawker, C. J.; Frechet, J. M. J. J. Am. Chem. Soc. 1993, 115, 11496 .

(11) Maraval, V.; Laurent, R.; Donnadieu, B.; Mauzac, M.; Caminade, A.-M.; Majoral, J.-P. J. Am. Chem. Soc. 2000, 122, 2499. or just one functional group ${ }^{15,16}$ at the periphery. However, the proposed use of dendrimers as nanosupports often requires that they provide a predefined spatial nanoenvironment, which in turn determines the necessary position of functional groups on their surfaces. The flexibility of dendrimers built up from aliphatic chains often precludes such a perfect spatial separation of the functional groups, as backfolding of the peripheral substituents can occur. ${ }^{17,18}$ Especially the study of chromophore-chromophore through-space interactions in such a system requires a rigid support since increased flexibility leads to undesired interactions such as aggregation, excimer formation, and dye self-quenching. ${ }^{19,20}$ Recently, the shape persistence of polyphenylene dendrimers has successfully been proven by applying advanced NMR studies ${ }^{21}$ and AFM measurements. ${ }^{22}$ In particular, solid-state NMR characterization has clearly proven that, due to the sterical hindrance imposed on a given phenyl group by its neighbors which are bound to the same core, only collective reorientations of all rings around one central core can take place. As a result, only limited dynamics which were identified as a well-localized, restricted reorientation of single terminal phenyl substituents around fixed axes could be observed. Furthermore, the stiffness and the size of these

(12) Newkome, G. R.; Weis, C. D.; Moorefield, C. N.; Baker, G. R.; Childs, B. J.; Epperson, J. Angew. Chem. 1998, 110, 318.

(13) Larre, C.; Bressolles, D.; Turrin, C.; Donnadieu, B.; Caminade, A.M.; Majoral, J.-P. J. Am. Chem. Soc. 1998, 120, 13070.

(14) Freeman, A. W.; Chrisstoffels, L. A. J.; Frechet, J. M. J. J. Org. Chem. 2000, 65, 7612.

(15) Bo, Z.; Schäfer, A.; Franke, P.; Schlüter, A. D. Org. Lett. 2000, 11,1645

(16) Hawker, C. J.; Frechet, J. M. J. Macromolecules 1990, 23, 4726.

(17) Bodnar, I.; Silva, A. S.; Deitcher, R. W.; Weisman, N. E.; Kim, Y. H.; Wagner, N. J. J. Polym. Sci. Part B: Polym. Phys. 2000, 38, 857.

(18) Scherrenberg, R.; Coussens, B.; Vliet, P. v.; Edouard, G.; Brackman, J.; Brabander, E. d.; Mortensen, K. Macromolecules 1998, 31, 456.

(19) Becker, S.; Klok, H. A.; Rodriguez-Hernandez, J.; Schuch, F.; Müllen, K. Macromolecules. Submitted for publication.

(20) Stewart, G. M.; Fox, M. A. J. Am. Chem. Soc. 1996, 118, 4354.

(21) Wind, M.; Wiesler, U.-M.; Saalwächter, K.; Müllen, K.; Spiess, H. W. Adv. Mater. 2001, 13, 752-756.

(22) Zhang, H.; Grim, P. C. M.; Foubert, P.; Vosch, T.; Vanoppen, P.; Wiesler, U. M.; Berresheim, A. J.; Müllen, K.; Schryver, F. C. D. Langmuir 2000, 16, 9009 . 
Scheme 1. Synthesis of the Asymmetrically Substituted Tetraphenylmethane Cores 2 (36\%), $3(47 \%)$, and 4 (6\%) ${ }^{a}$

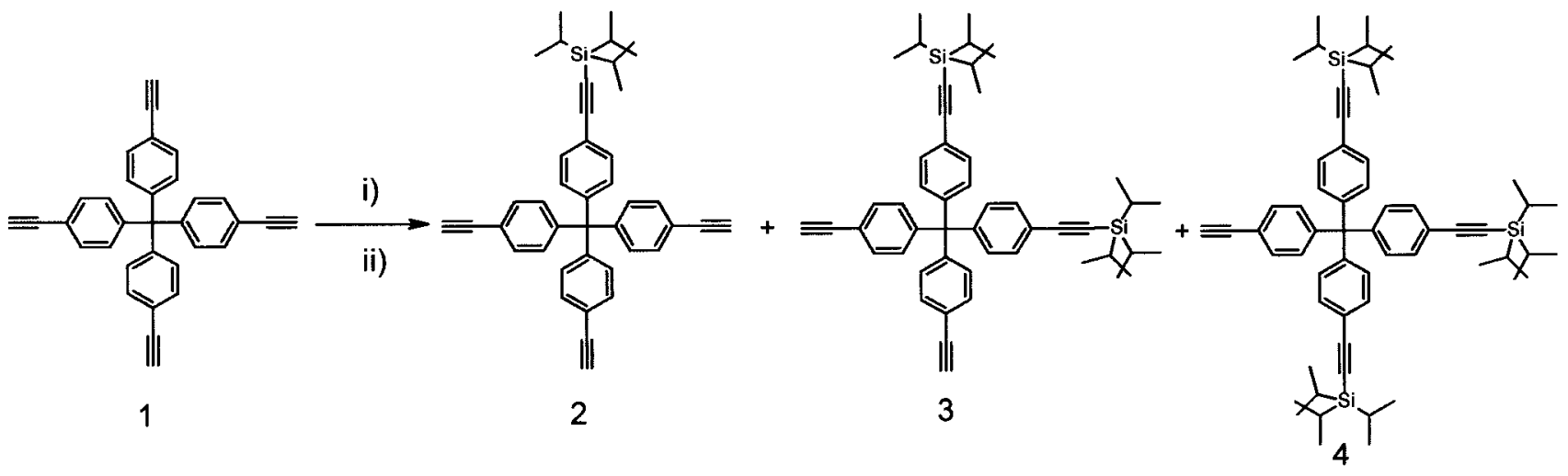

${ }^{a}$ Conditions: (i) $n$-BuLi, THF, $2 \mathrm{~h},-78^{\circ} \mathrm{C}$; (ii) triisopropylsilyl chloride, $2 \mathrm{~h}$, room temperature.

Scheme 2. Synthesis of BTI-Tetraphenylcyclopentadienone 12

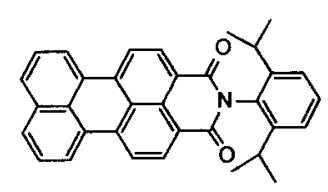

5

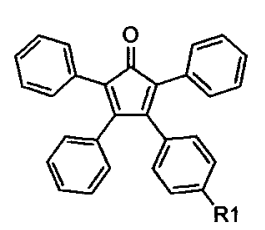

6: $\mathbf{R 1}=\mathbf{P M I}$

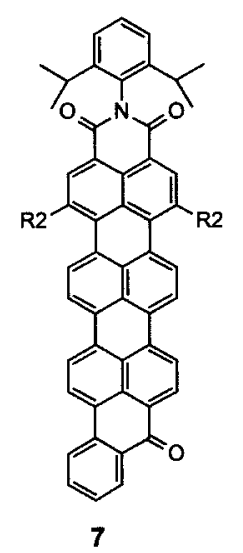

7

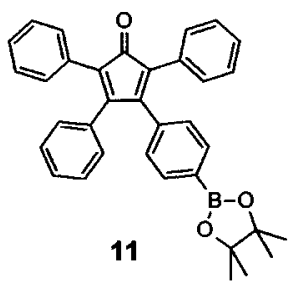

$\overrightarrow{79 \%}$

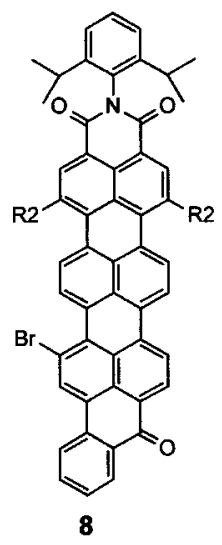

$87 \%$
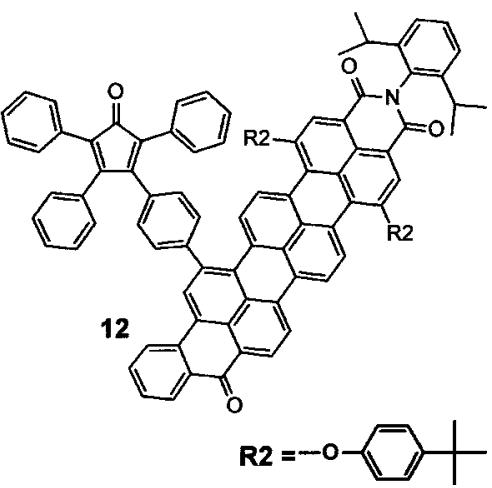

dendrimers have also been determined by PFM-AFM (pulsed force mode) measurements. ${ }^{22}$ The construction of polyphenylene dendrimers via the Diels-Alder reaction of a core molecule carrying free ethynyl units with tetraphenylcyclopentadienones has been the subject of many publications from our group. ${ }^{23-26}$ The reaction proceeds with concomitant extrusion of $\mathrm{CO}$ and allows a quantitative formation of the resulting dendrimer. Functional groups are introduced at the periphery by using tetraphenylcyclopentadienone building units carrying the appropriate functionality. ${ }^{27}$ Besides the topologically defined location of the functions, a further advantage of this system for

(23) Morgenroth, F.; Reuther, E.; Müllen, K. Angew. Chem., Int. Ed. Engl. 1997, 36, 631.

(24) Morgenroth, F.; Kübel, C.; Müllen, K. J. Mater. Chem. 1997, 7 , 1207.

(25) Morgenroth, F.; Müllen, K. Tetrahedron 1997, 53, 15349.

(26) Muller, M.; Kübel, C.; Morgenroth, F.; Iyer, V. S.; Müllen, K Carbon 1998, 36, 827. 212,1 . the use as a nanosupport is the absence of functional groups within the dendritic scaffold, which is therefore highly chemically and thermally stable as well as inert to the introduced groups. Based on a convergent approach toward polyphenylene dendrimers, we now present dendrimers whose surface is coated asymmetrically with chromophores. Furthermore, the synthesis of a multichromophore consisting of three donor chromophores and one acceptor chromophore in a defined spatial arrangement will be described. So far, there exist some examples of dendrimers whose surface is completely decorated with one type of chromophore. ${ }^{28-32}$ To the best of our knowledge, the attachment of an increasing number of single chromophores to

(28) Gensch, T.; Hofkens, J.; Heirmann, A.; Tsuda, K.; Verheijen, W.; Vosch, T.; Christ, T.; Basché, T.; Müllen, K.; Schryver, F. C. D. Angew. Chem., Int. Ed. Engl. 1999, 38, 3752.

(29) Yeow, E. K. L.; Ghiggino, K. P.; Reek, J. N. H.; Crossley, M. J.; Bosman, A. W.; Schenning, A. P. H. J.; Meijer, E. W. J. Phys. Chem. B 2000, 104, 2596.

(30) Vögtle, F.; Gestermann, S.; Kauffmann, C.; Ceroni, P.; Vicinelli, V.; Cola, L. D.; Balzani, V. J. Am. Chem. Soc. 1999, 121, 12161. 
Scheme 3. Synthetic Route toward Unfunctionalized and Monofunctionalized Dendrons

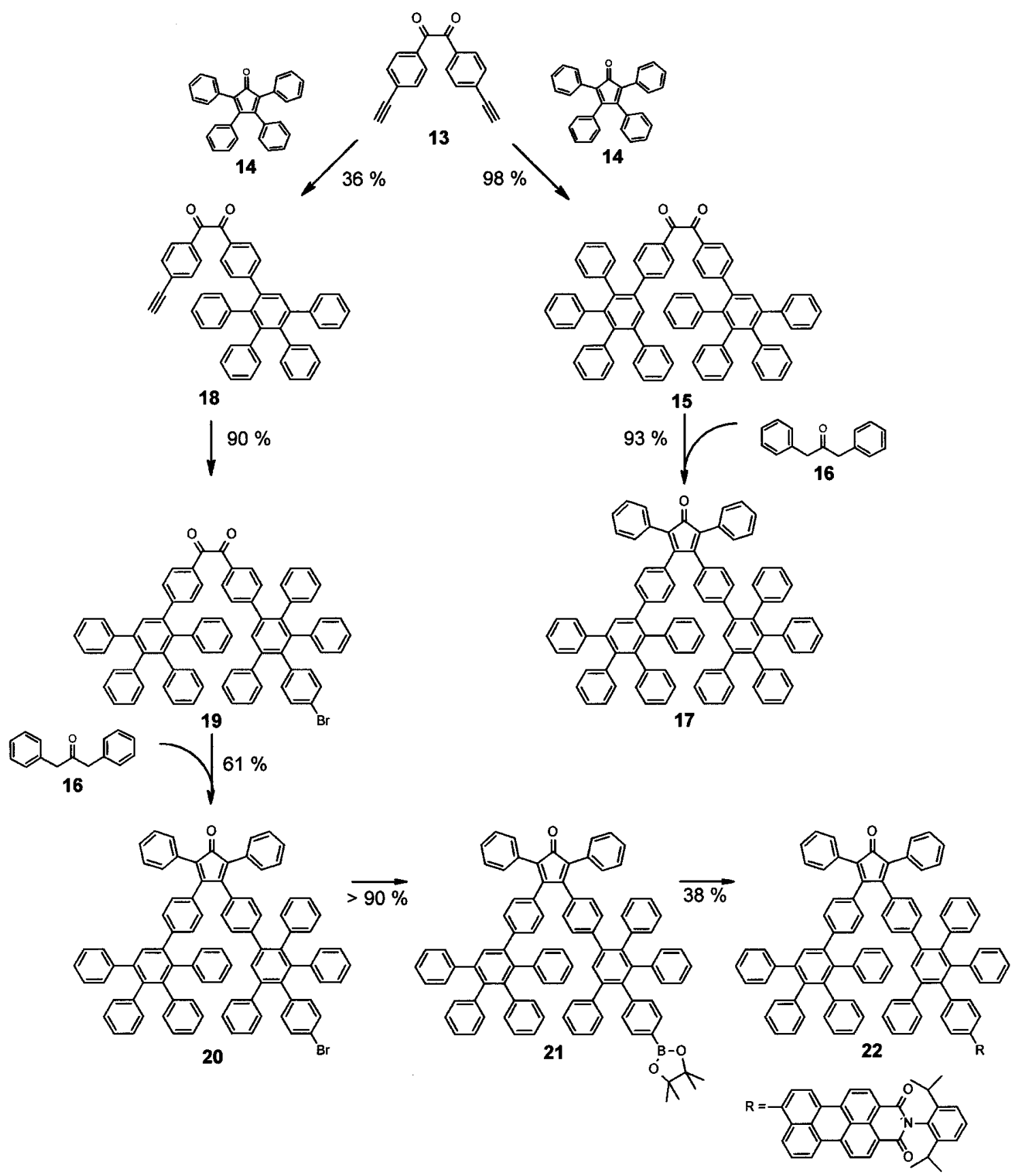

a dendritic core which results in an asymmetrically substituted surface has not been described previously. Recently, some examples of dendrimers carrying two different types of chromophores (a donor and an acceptor) have been published. ${ }^{31,33-39}$

\footnotetext{
(31) Gilat, S. L.; Adronov, A.; Fréchet, J. M. J. J. Org. Chem. 1999, 64, 7474.

(32) Jiang, D. L.; Aida, T. J. Am. Chem. Soc. 1998, 120, 10895.

(33) Shortreed, M. R.; Swallen, S. F.; Shi, Z. Y.; Tan, W. H.; Xu, Z. F.; Devadoss, C.; Moore, J. S.; Kopelman, R. J. Phys. Chem. B 1997, 101, $6318-6322$

(34) Adronov, A.; Gilat, S. L.; Fréchet, J. M. J.; Ohta, K.; Neuwahl, F. V. R.; Fleming, G. R. J. Am. Chem. Soc. 2000, 122, 1175.

(35) Adronov, A.; Frechet, J. M. J. Chem. Commun. 2000, 18, 1701

(36) Gilat, S. L.; Adronov, A.; Fréchet, J. M. J. Angew. Chem., Int. Ed. 1999, 38, 1422-1427.

(37) Devadoss, C.; Bharathi, P.; Moore, J. S. J. Am. Chem. Soc. 1996, 118,9635 .

(38) Maruo, N.; Uchiyama, M.; Kato, T.; Arai, T.; Akisada, H.; Nishino, N. Chem. Commun. 1999, 2057-2058.

(39) Plevoets, M.; Vögtle, F.; Cola, L. D.; Balzani, V. New J. Chem. $1999,23,63-69$.
}

However these antenna systems cannot be used for single molecule spectroscopy (SMS) where the photochemical stability of the chromophores and the emission at higher wavelength is a key concern. We chose chromophores of the rylene series due to their outstanding properties, e.g. chemical and photochemical stability, which make them attractive candidates for SMS. ${ }^{40,41}$ SMS is an excellent method for the measurement of spatial, conformational, and time-dependent inhomogenities of chromophores in a close vicinity, e.g. energy transfer. ${ }^{41-43}$ These investigations are important for the better understanding of biological processes such as energy transfer processes involved

(40) Lee, S. K.; Zu, Y. B.; Herrmann, A.; Geerts, Y.; Müllen, K.; Bard, A. J. J. Am. Chem. Soc. 1998, 141, 3513.

(41) Hofkens, J.; Maus, M.; Gensch, T.; Vosch, T.; Cotlet, M.; Kohn, F.; Herrmann, A.; Müllen, K.; Schryver, F. C. D. J. Am. Chem. Soc. 2000, 122,9278 .

(42) Moerner, W. E.; Orrit, M. Science 1999, 283, 1670.

(43) Weiss, S. Science 1999, 283, 1676. 
Scheme 4. General Method for the Synthesis of Asymmetrically Substituted Polyphenylene Dendrimers up to the Second Generation $^{a}$
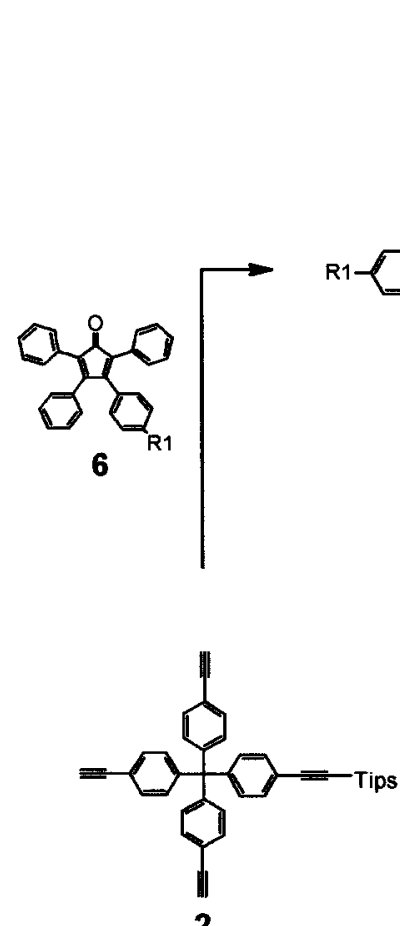

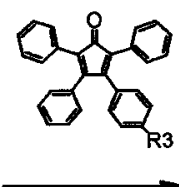

12) $R 3=B T I$

14) $R 3=H$

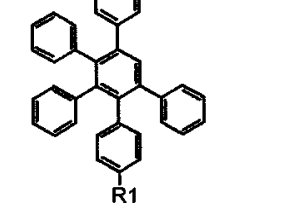

23c) $P G=\operatorname{Tips}(95 \%)$

24c) $P G=H(76 \%)$

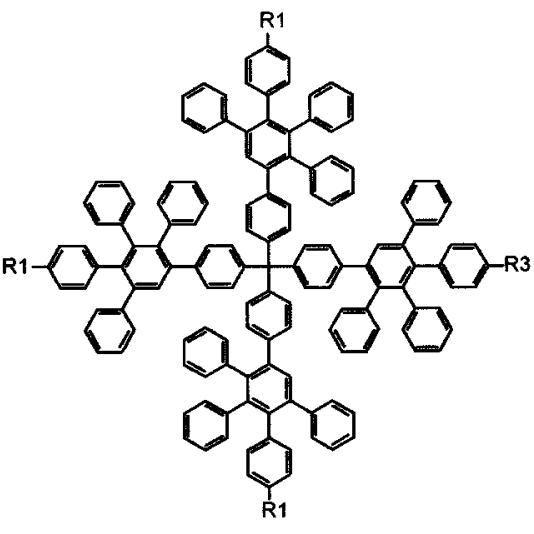

25c) $R 3=H(91 \%)$

25e) $R 3=$ BTI ( $39 \%)$

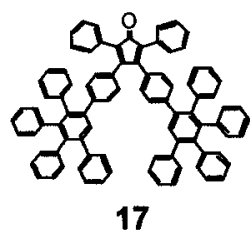

17

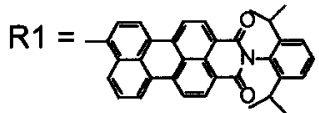

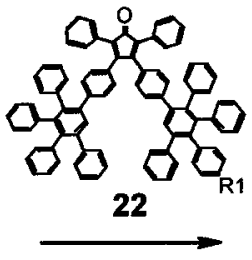

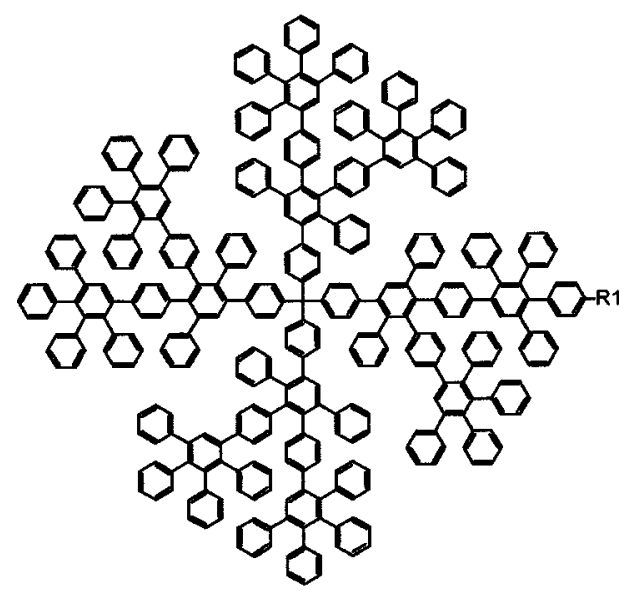

28 a ( $88 \%)$

26a) $P G=\operatorname{Tips}(70 \%)$

27a) PG = H ( $94 \%)$

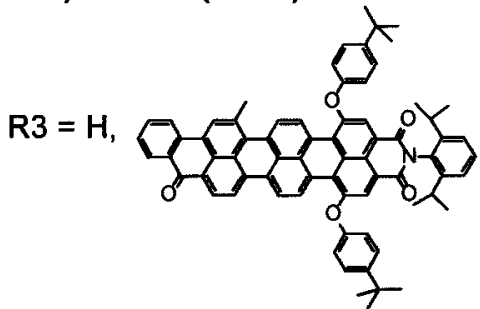

${ }^{a}$ Representatively, this method is only shown for the case of a 3:1 ratio of the functionalities at the periphery.

in photosynthesis ${ }^{44-48}$ as well as for applications in the field of light harvesting systems. ${ }^{49,50}$

(44) Knox, R. S. Primary Processes of Photosynthesis; Elsevier: Amsterdam, The Netherlands, 1977; Vol. 2.

(45) Deming-Adams, B. Biochim. Biophys. Acta 1990, 1020, 1.

(46) Goedheer, J. D. Biochim. Biophys. Acta 1969, 172, 252.

(47) Cogdell, R. J.; Frank, H. A. Biochim. Biophys. Acta 1987, 895, 63.

(48) McDermott, G.; Prince, S. M.; Freer, A. A.; HawthornthwaiteLawless, A. M.; Papiz, M. Z.; Cogdell, R. J.; Isaacs, N. W. Nature 1995, $374,517$.

\section{Results and Discussion}

Synthesis of the Asymmetric Core. The synthesis of asymmetric polyphenylene dendrimers via the Diels-Alder reaction is based on a tetrahedral core carrying both free and protected ethynyl units. The key feature of such a core molecule is that the Diels-Alder reaction with tetraphenylcyclopentadienones proceeds only with the unprotected ethynyl units resulting in an asymmetrical dendrimer growth. Such a core is 

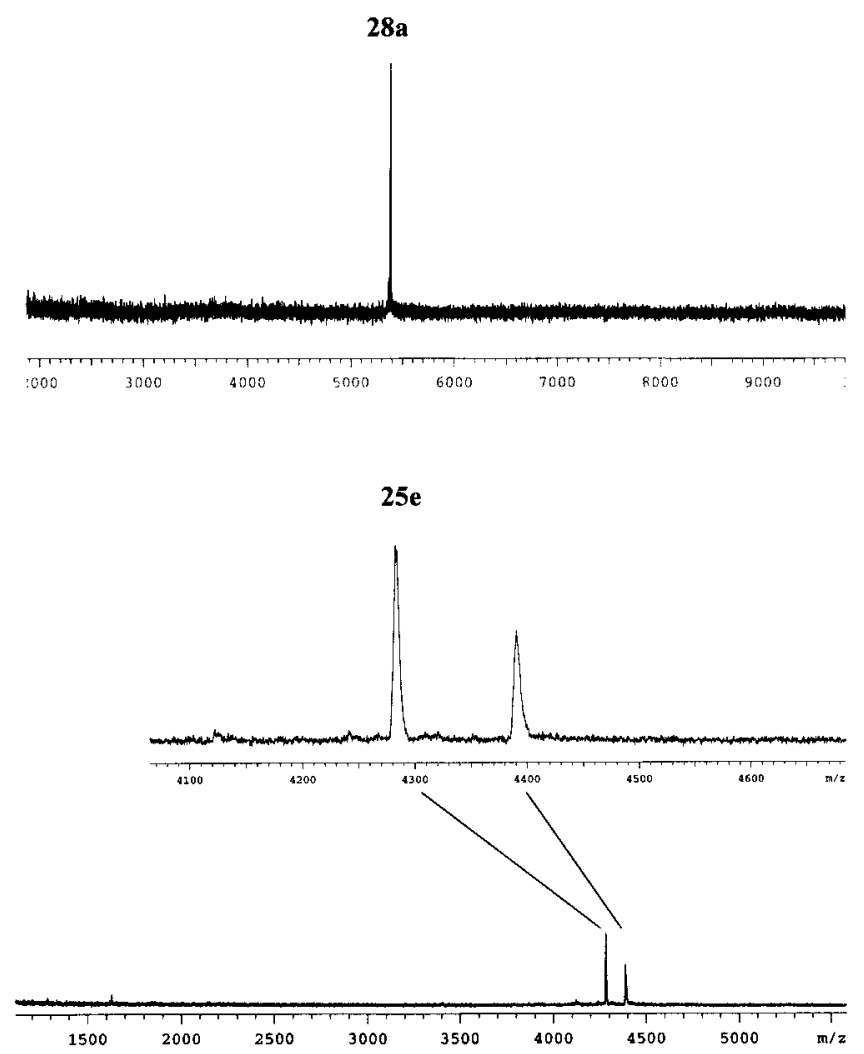

Figure 1. MALDI-TOF mass spectra of the second generation polyphenylene dendrimer carrying one single PMI chromophore 28a and the bichromophore 25e. The calculated weight is $5365 \mathrm{~g} / \mathrm{mol}$ for 28a and $4283 \mathrm{~g} / \mathrm{mol}$ for $25 \mathrm{e}$.

obtained by treating tetrakis(4-ethynylphenyl)methane (1) with a controlled amount of $n$-BuLi (see below) at $-78{ }^{\circ} \mathrm{C} .{ }^{51,52}$ The reaction mixture is then stirred for an additional $2 \mathrm{~h}$ under argon after addition of a 2-fold excess of triisopropylsilyl chloride (TipsCl), relative to the amount of $n$-BuLi. A statistical product mixture of one-, two-, three-, and 4-fold triisopropylsilylprotected derivatives results (Scheme 1, compounds 2, 3, and 4), which is separated via column chromatography. The approximate number of Tips groups is adjustable via the amount of $n$-BuLi used: for example, a 2.2-fold excess of $n$-BuLi gives 3 as the main product in $47 \%$ yield. After separation of the main product via column chromatography, the remaining unresolved reaction mixture can be deprotected completely with fluoride salts. In this way the starting compound $\mathbf{1}$ can be recovered in nearly quantitative yield. Via this reaction sequence compounds $\mathbf{2}, \mathbf{3}$, and $\mathbf{4}$ can readily be synthesized in gram scale.

Synthesis of the Chromophore-Labeled Branches. In the following we will focus on the introduction of a distinct number of chromophores at the periphery of first- and second-generation polyphenylene dendrimers. The essential building unit for the construction of fluorescent first-generation dendrimers is a chromophore-labeled tetraphenylcyclopentadienone. Secondgeneration dendrimers with a varying amount of chromophores are synthesized via the convergent-growth approach by using dendrons (dendrimer branches) carrying the chromophore. We chose two chromophores of the rylene series: 7-N-(2,6diisopropylphenyl)perylene-3,4-dicarboximide (PMI, 5) and

(49) Zuber, H.; Brunisholz, R. A. Structure and Function of Antenna Polypeptides and Chlorophyll-Protein Complexes: Principles and Variability; CRC Press: Boca Raton, FL, 1991.

(50) Scholes, G. D.; Fleming, G. R. J. Phys. Chem. B 2000, 104, 1854.

(51) Galoppini, E.; Gilardi, R. Chem. Commun. 1999, 2, 173

(52) Mongin, O.; Gossauer, A. Tetrahedron 1997, 53, 6835.
$N$-(2,6-diisopropylphenyl)-1,6-di(4-tert-butylphenoxy)-11(CO),12-benzoylterrylen-3,4-dicarboximide (BTI, 7), due to their outstanding photophysical properties and the spectral overlap between the PMI-donor emission and the BTI-acceptor absorption. A PMI-labeled tetraphenylcyclopentadienone $\mathbf{6}$ has already been reported by us. ${ }^{28,53}$ The attempted synthesis of tetraphenylcyclopentadienone $\mathbf{1 2}$ carrying a BTI chromophore by analogous chemistry was not successful. Therefore we have applied a new reaction sequence starting from 3-(4-bromophenyl)-2,4,5-triphenylcyclopentadienone (9), which is converted into a protected boronic acid $\mathbf{1 1}$ by using the commercially available bispinacolatodiboron $\mathbf{1 0} .{ }^{54}$ Compound $\mathbf{8}$ then reacts with 11 via a Suzuki coupling ${ }^{55}$ leading to $\mathbf{1 2}$ in $69 \%$ yield.

The build-up of the BTI-substituted tetraphenylcyclopentadienone 12 required the new BTI chromophore $\mathbf{8}$ carrying a single bromo function. Compound $\mathbf{8}$ is prepared via bromination of BTI 7 with bromine in trichloromethane at room temperature in good yield (79\%). Reaction monitoring via thin-layer chromatography or FD-mass spectrometry is indispensable to minimize formation of multiply brominated byproducts which appear after prolonged reaction times. The key compound for the synthesis of polyphenylene dendrons is $4,4^{\prime}$-diethynylbenzil (13), which contains two free ethynyl dienophile units and one ethanedione function. This starting material is prepared via Sonogashira coupling ${ }^{56}$ of triisopropylsilylacetylene and $4,4^{\prime}$ dibromobenzil, followed by deprotection with $\mathrm{KF}$ in DMF $(70 \%$, yellow crystals). After Diels-Alder cycloaddition with an excess of tetraphenylcyclopentadienone (14) in refluxing $o$-xylene, the benzil $\mathbf{1 5}$ is obtained as a pale yellow amorphous powder (Scheme 3). The Knoevenagel condensation of compound $\mathbf{1 5}$ with 1,3-diphenylacetone (16) in the presence of tetrabutylammonium hydroxide leads to the corresponding dendron $\mathbf{1 7}$ in $85 \%$ yield. The synthesis of an asymmetrically functionalized dendron 20 carrying one single bromo group also starts from diethynylbenzil 13 outlined in Scheme 3. Separation of unwanted byproducts $\mathbf{1 3}$ and $\mathbf{1 5}$ is achieved via column chromatography. In the following, the cycloaddition of $\mathbf{1 8}$ and $\mathbf{9}$ gives $\mathbf{1 9}$ in nearly quantitative yield. 19 is then converted into the dendron 20 via a Knoevenagel condensation with 1,3-diphenylacetone (16) as described above. The formation of the protected boronic acid $\mathbf{2 1}$ is accomplished in nearly quantitative yield via a reaction of $\mathbf{2 0}$ with bispinacolatodiboron 10. 21 is purified via filtration over a short pad of silica gel. In the last step, the Suzuki coupling of $\mathbf{2 1}$ and $N$-(2,6-diisopropylphenyl)-9-bromoperylene-3,4-dicarboximide leads to the target molecule: a mono-PMI-substituted dendron $\mathbf{2 2}$ that is isolated as a dark red solid in moderate yields (73\%). The key feature of the boronic acid-functionalized tetraphenylcyclopentadienone building unit 21 is the ease of introduction of new functional groups, via simple coupling with a bromo- or iodo-substituted aromatic compound carrying the desired functionality.

Synthesis of the Asymmetrically Substituted Polyphenylene Dendrimers. Starting from the pure partially protected cores (2, 3, or 4), Diels-Alder cycloaddition with the PMI tetraphenylcyclopentadienone $\mathbf{6}$ introduces from one up to four PMI chromophore units. Representatively, this reaction sequence is shown in Scheme 4 only for core 2 . To contribute to the clarity of the molecular structure, the number of the dendrimer corresponds to a series of structurally similar dendrimers and

(53) Weil, T.; Herrmann, A.; Müllen, K. Chem. Eur. J. Submitted for publication.

(54) Ishiyama, T.; Murata, M.; Miyaura, N. J. Org. Chem. 1995, 60, 7508.

(55) Watanabe, T.; Miyaura, N.; Suzuki, A. Synlett 1992, 3, 207.

(56) Takahashi, S.; Kuroyama, Y.; Sonogashira, K.; Hagihara, N. Synthesis 1980, 627. 


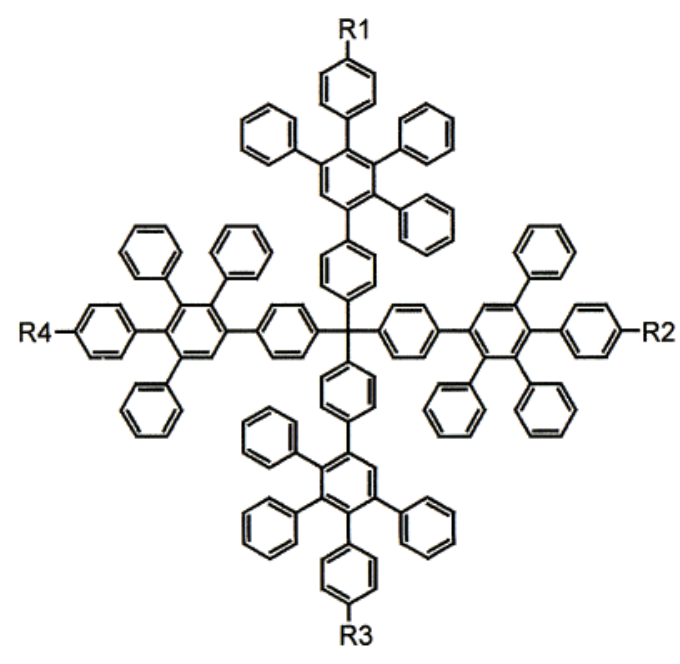

25

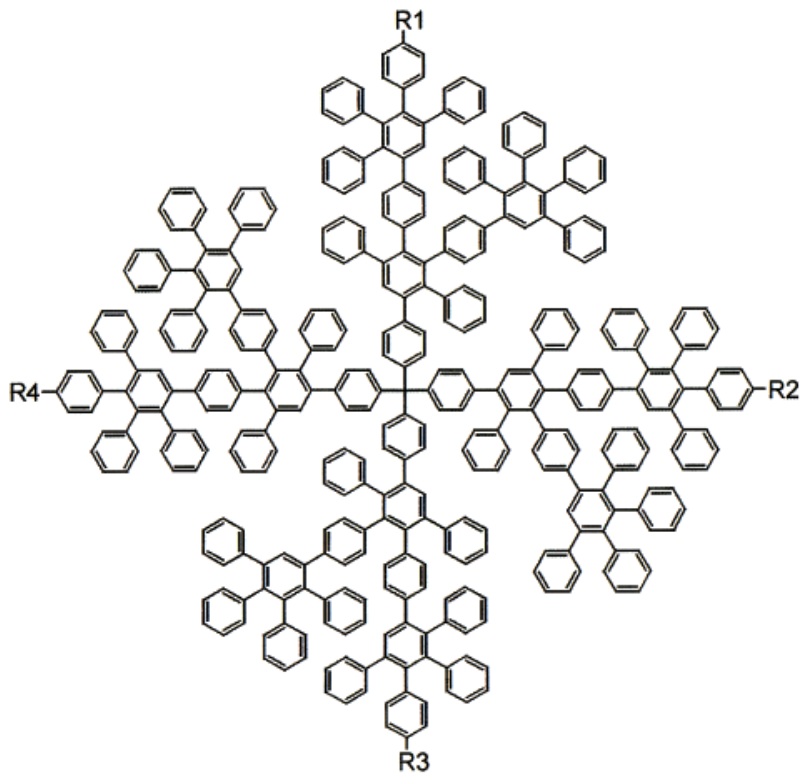

28

25a $/$ 28a $R 1=P M I ; R 2, R 3, R 4=H$

25b / 28b R1, R2 = PMI; R3, R4 = H

25c $/$ 28c R1, R2, R3 = PMI; R4 = H

25d / 28d R1, R2, R3, R4 = PMI

25e

$\mathrm{R} 1, \mathrm{R} 2, \mathrm{R} 3=\mathrm{PMI} ; \mathrm{R} 4=\mathrm{BTI}$

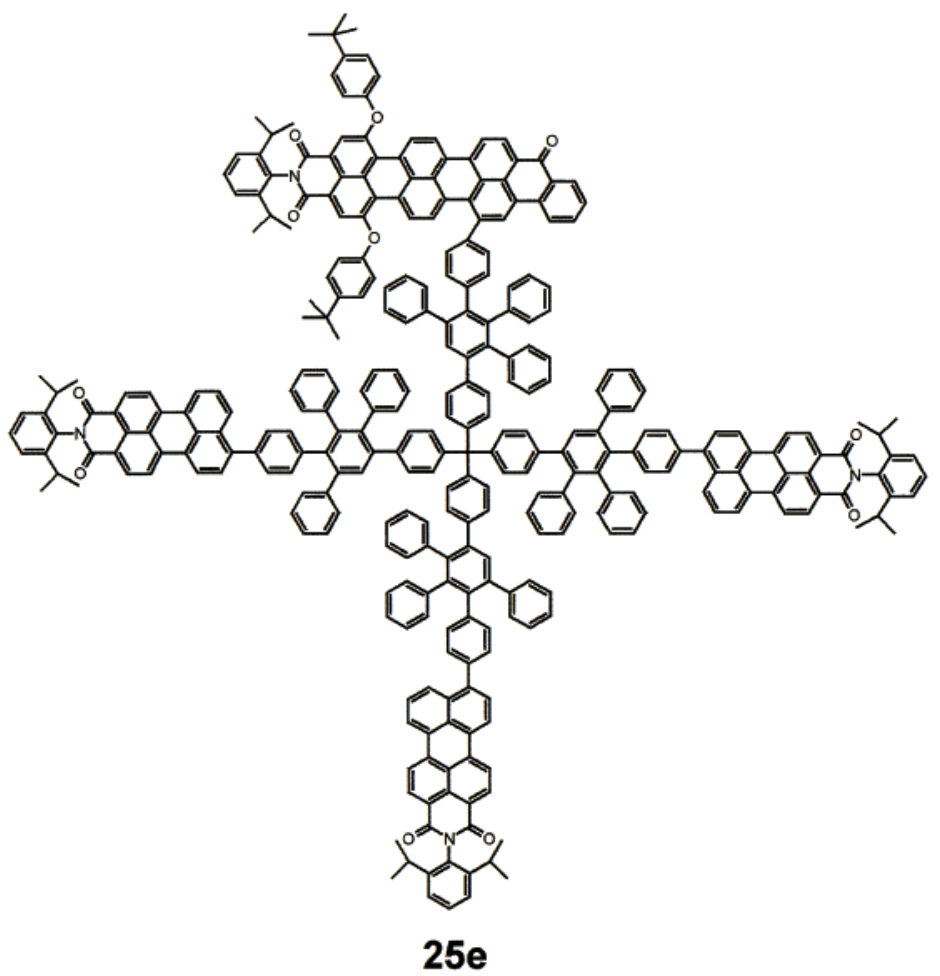

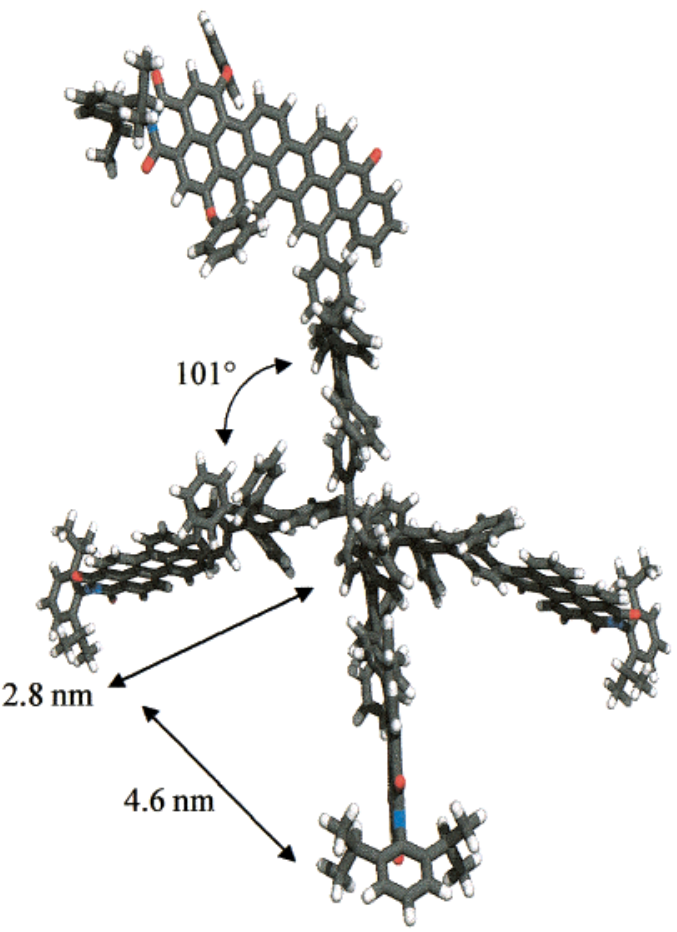

25e

Figure 2. First- and second-generation polyphenylene dendrimers coated with an increasing number of PMI chromophores (25a-d/ $\mathbf{2 8 a}-\mathbf{d}$ ) and 3D model of the bichromophore $25 \mathrm{e}$.

the alphabetic letter describes one dendrimer of this series. Deprotection of the remaining triisopropylsilyl-protected ethynyl unit of the dendrimer 23c with $\mathrm{Bu}_{4} \mathrm{NF} / \mathrm{THF}$ led to $\mathbf{2 4 c}$. Subsequent Diels-Alder reaction of $\mathbf{2 4 c}$ with a tetraphenylcyclopentadienone coated with a functionality "R3" 12/14 gave the first-generation polyphenylene dendrimer $25 \mathbf{c} / \mathbf{2 5 e}$. For $\mathrm{R} 3=\mathrm{H}, \mathbf{2 5} \mathbf{c}$, a dendrimer with an asymmetric PMI distribution at the periphery, was obtained as a bright red powder. The firstgeneration polyphenylene dendrimers substituted with one, two, and four PMI units (25a, 25b, and 25d) have been realized in 


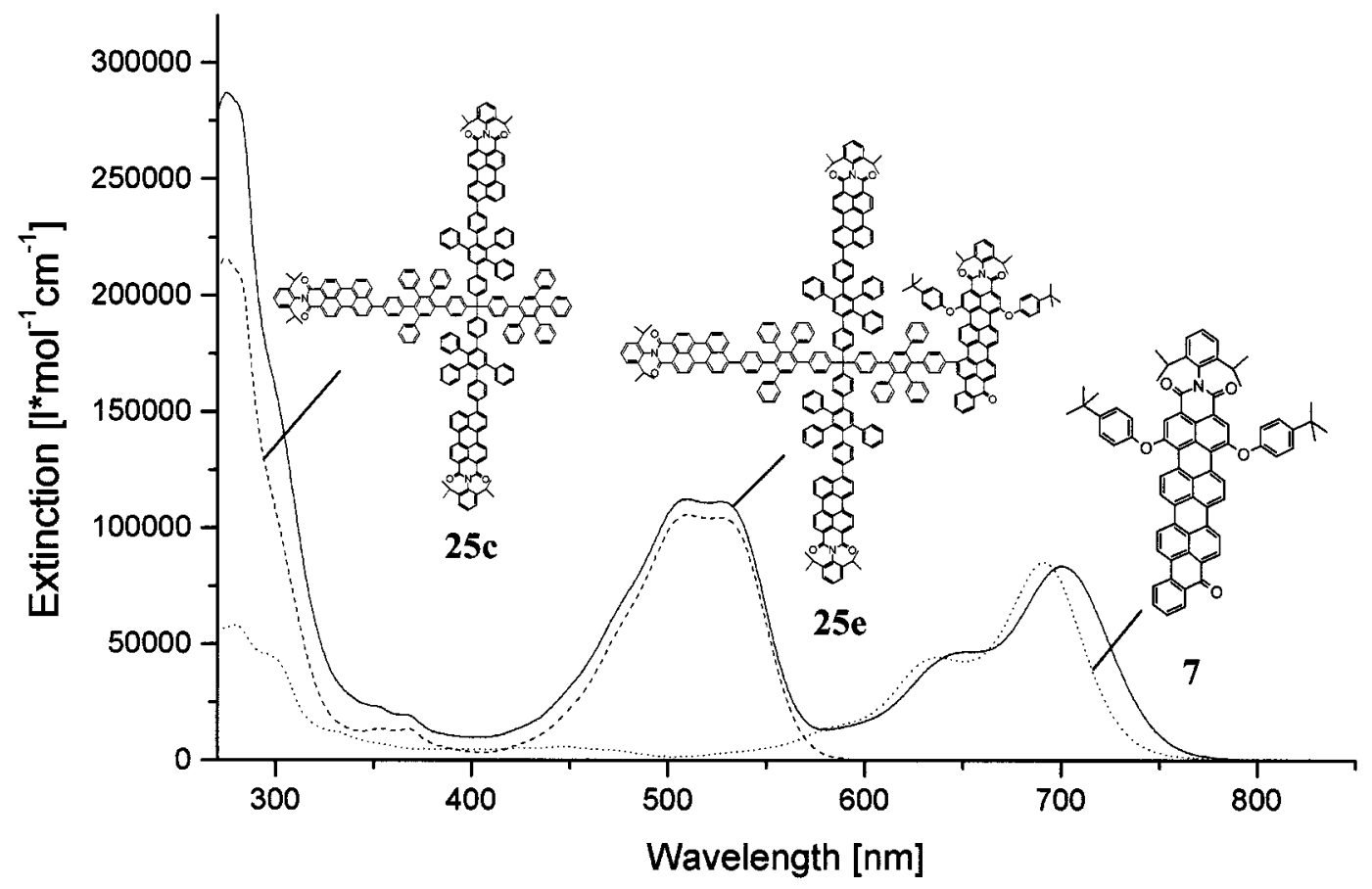

Figure 3. UV/vis absorption spectra of $7, \mathbf{2 5}$, and $25 \mathbf{e}\left(\mathrm{CHCl}_{3}\right)$.

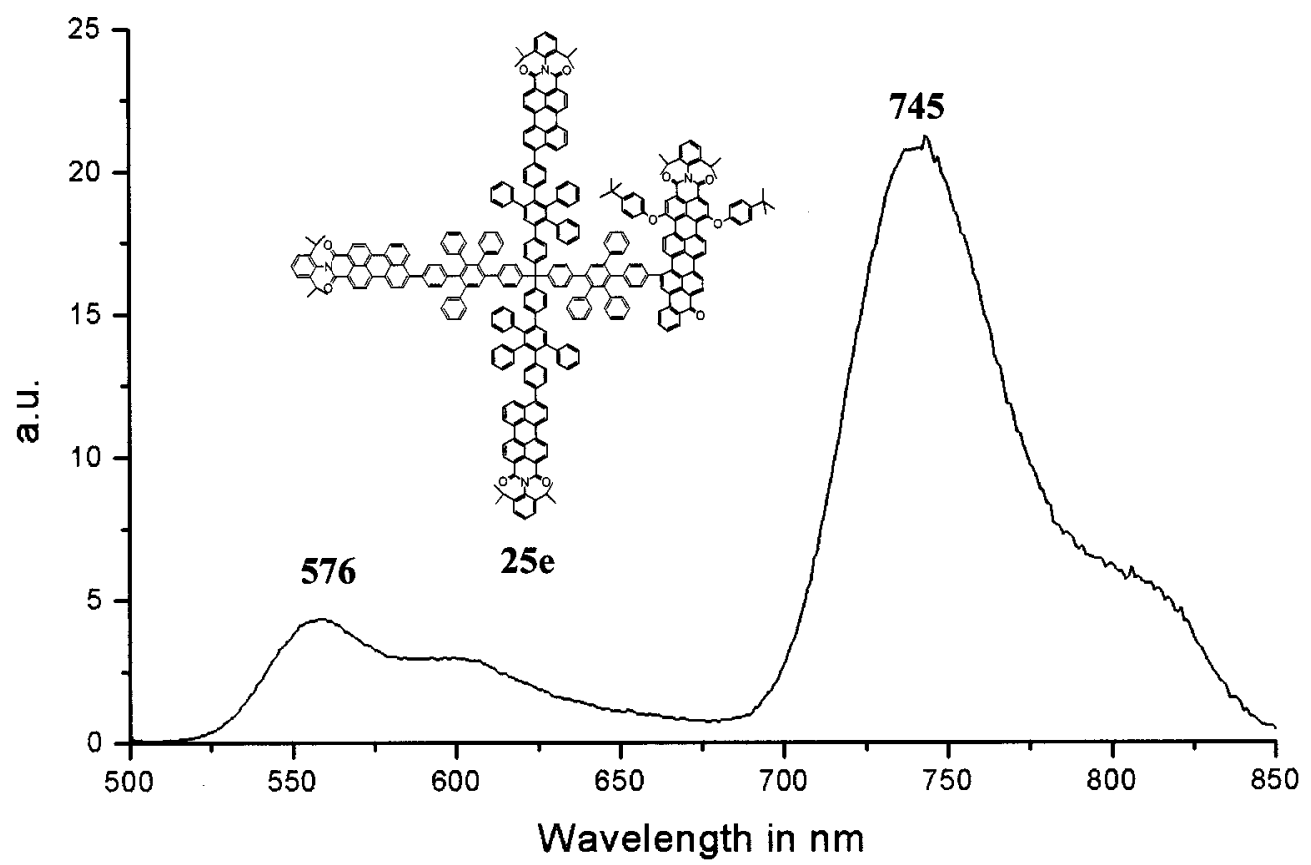

Figure 4. Fluorescence emission spectrum of $25 \mathrm{e} ; \lambda_{\mathrm{exc}}=500 \mathrm{~nm}$ (toluene).

the same way by starting from core 4,3 , or 1 as shown in Scheme 4. By using the BTI-functionalized tetraphenylcyclopentadienone building unit $12(\mathrm{R} 3=\mathrm{BTI})$ to $\mathbf{2 4 c}$, polyphenylene dendrimer 25e carrying both PMI and BTI chromophores was obtained.

The synthesis of the corresponding second-generation polyphenylene dendrimers was performed by starting from core $\mathbf{2}$ and Diels-Alder reaction with dendron 17. Deprotection of the remaining triisopropylsilyl groups with $\mathrm{Bu}_{4} \mathrm{NF}$ and Diels-Alder reaction with the PMI-substituted dendron 22 gave the secondgeneration polyphenylene dendrimer 28a carrying one single PMI chromophore. The synthesis of the second-generation polyphenylene dendrimers decorated with a higher number of chromophores has been carried out analogously. Two exemplary mass spectra of the second-generation dendrimer 28a decorated with one PMI chromophore and the multichromophore 25e are given in Figure 1, showing only one single peak corresponding to the molecular mass. In case of the multichromophore, an additional molecular mass peak $[\mathrm{M}+\mathrm{Ag}]^{+}$cluster was detected. The perfect agreement between the calculated and experimentally determined $\mathrm{m} / \mathrm{z}$ ratios for different generations of dendrimers confirms their monodispersity.

Figure 2 gives an overview of the herein reported target molecules. Molecular mechanics calculations reveal a diameter of about $2.5 \mathrm{~nm}$ for the first-generation series and $4.5 \mathrm{~nm}$ for the second-generation series. The minimized structures of the first-generation dendrimers have been obtained by applying the MM2 (MM+) force field as implemented in the software package HyperChem 6.0 (Hypercube Inc.). In this way, the dendrimer and the PMI chromophores have been calculated 
separately and the global minimum has been obtained for both separate molecules. The minimum structure of the tetrahedral core has been obtained by applying the same strategy that is already well documented in the literature.$^{57}$ In the last step, the chromophores are attached to the dendrimer surface and the whole molecule is optimized with the $\mathrm{MM}+$ force field. Figure 2 shows one possible low-energy geometry of the multichromophore 25e, which was found to be sufficient to evaluate the diameter of the molecule (diameter of about $2.7 \mathrm{~nm}$ ) and the approximate position of the chromophores with respect to each other. According to the simulation, the chromophores are situated exclusively on the surface of the dendrimer where their spatial arrangement is well-defined.

Absorption and Fluorescence Measurements. 25e has been obtained as a dark purple powder and shows good solubility in most organic solvents. The color corresponds to the spectral sum of the red PMI and the blue BTI. The absorption spectra of the multichromophore 25e, the 3-fold PMI substituted dendrimer $\mathbf{2 5 c}$, and the unfunctionalized BTI chromophore 7 in chloroform are depicted in Figure 3. The spectrum of 25c exhibits absorption maxima at $509\left(112352 \mathrm{M}^{-1} \mathrm{~cm}^{-1}\right)$ and $527\left(111256 \mathrm{M}^{-1} \mathrm{~cm}^{-1}\right) \mathrm{nm}$ while the single BTI chromophore absorbs at $691\left(85322 \mathrm{M}^{-1} \mathrm{~cm}^{-1}\right) \mathrm{nm}$. The multichromophore 25e displays absorption maxima at $508\left(112352 \mathrm{M}^{-1} \mathrm{~cm}^{-1}\right)$, $527\left(111256 \mathrm{M}^{-1} \mathrm{~cm}^{-1}\right)$, and $700\left(83613 \mathrm{M}^{-1} \mathrm{~cm}^{-1}\right) \mathrm{nm}$, corresponding to the absorption of the PMI and the BTI units. Therefore the absorption spectrum of $\mathbf{2 5} \mathbf{e}$ can be approximated as a superposition of the spectra of the constituent moieties. In view of the well-separated absorption envelopes it is possible to excite the specific chromophores. The fluorescence quantum yields $\left(\phi_{\mathrm{f}}=0.98 \pm 0.05\right)$ of the dendrimers $\mathbf{2 5 a}-\mathbf{d}$ and $\mathbf{2 8 a}-\mathbf{d}$ are practically identical within experimental error to that of the free PMI unit: In the multichromophore 25e the fluorescence quantum yield for the PMI emission is decreased by $96 \%$, thus indicating efficient energy transfer from the PMI to the BTI is occurring.

In the next step we addressed the possibility of energy transfer between the two chromophores in compound 25e. After excitation at $\lambda_{\mathrm{exc}}=500 \mathrm{~nm}$ (near $\lambda_{\max }$ for PMI), the resulting fluorescence spectrum consists of PMI as well as BTI emission (Figure 4). The BTI fluorescence can be explained by an excitation energy transfer from the PMI to the BTI chromophore. In this case, more than $96 \%$ of the energy harvested by the peryleneimide chromophores is transferred and trapped in the terryleneimide chromophore. This energy-transfer process can

(57) Brocorens, P.; Zojer, E.; Cornil, J.; Shuai, Z.; Leising, G.; Mullen, K.; Bredas, J. L. Synth. Met. 1999, 100, 141-162. be described perfectly with Förster energy transfer theory, which is discussed in more detail in the following article. ${ }^{58}$

\section{Conclusion}

We have presented a convergent-growth approach toward structurally well-defined polyphenylene dendrimers bearing an asymmetrical distribution of functional groups at the periphery. Such a well-defined distribution of functionalities is based on a "desymmetrization" step as the synthetic key point. The use of polyphenylene dendrimers as an inert nanosupport opens up the way for studying interactions of two different types of functional groups where the distances and the positions of the functionalities are predefined. Following this idea, we have shown the synthesis of a multichromophore consisting of perylene and terrylene chromophores that is also suitable for single molecule spectroscopy. This system behaves as a dendritic light harvesting antenna that shows an energy transfer from the perylene chromophores toward the terrylene chromophore. We are currently working on the introduction of biologically active groups at the periphery of these highly fluorescent molecules. The introduction of a biotin unit on one site of the dendrimer and multiple chromophores on the others would lead to highly fluorescent molecules bearing an affinity to a target molecule (e.g., a protein). However, the application of thus functionalized dendrimers as fluorescent markers in the area of visualization (e.g., cellular processes) often requires water solubility. A combination of multifunctionalization, water solubility, and fluorescence is crucial.

Acknowledgment. This research was supported by the TMR European Research Program through the SISITOMAS project, the Volkswagen-Stiftung, and the Bundesministerium für Bildung and Forschung. U.-M. Wiesler would like to thank the Fonds der Chemischen Industrie for a Ph.D. grant. Last but not least, we would like to thank S. Spang and C. Beer for their synthesis support.

Supporting Information Available: Experimental procedures for the synthesis of all dendritic compounds including analytical data (PDF). This material is available free of charge via the Internet at http://pubs.acs.org.

\section{JA010579G}

(58) Maus, M.; De, R.; Lor, M.; Weil, T.; Mitra, S.; Wiesler, U.-M. Herrmann, A.; Hofkens, J.; Vosch, T.; Müllen, K.; De Schryver, F. C. J. Am. Chem. Soc. 2001, 123, 7668-7676. 